diphtheritic membrane by putting a piece in a test tube with some of the fluid, and nuaintaining it at a temperature of from $100^{\circ}-110^{\circ} \mathrm{F}$., when it will be seen to be digested rapidly.

I should not think of publishing the results of a single case were it not that I shall not for a long while have an opportunity of trying pepsin again, and by publishing this I thought others might be led 10 try it; and if in a larger number of cases it $b$ the rest of the so-culled solvents. If not, it can come into general use.

Messrs. Bullock and Co., of Hanover-street, who have shown the greatest kindness in helping me, have prepared a solution of pepsin without so much glycerine as that ordinarily sold by them. The advantage of this is that it passes more readily through the fine tubes of the Siegle spray. They require four days' notice to prepare this special form.

Carshalton.

\section{CASE OF GALVANO-PUNCTURE IN AORTIC ANEURISM ; SUCCESSFUL RESULT.}

BY RICHARD CANNON, L.K.Q.C.P., L.R.C.S.I., M.D. UNIVERSITY OF CHILI, LATE SURGEON R.N., ETC.

G. T- aged forty-two, a publican, a native of the north of Ireland, a resident in Valparaiso for many years, not given to habitual intemperance, with a rheumatic history, tall, of spare habit, with closed pupil and opaque lens capsule in right eye, applied to me towards the middle of the year 1879, complaining of pain to the right side of the sternum in the parietes of the thorax, accompanied by a dry cough, and a feeling of tension, with pain shooting to the shoulder-joint. I diagnosed aneurism of the aorta, about the origin of the arteria innominata, and based my diagnosis solely on the feeling of increased pulsation, and the accentuation of the heart sounds in the aorta, as there was no bruit to be heard, no dyspncea, aphonia, or dysphagia; no difference in radial pulses, no pupillary evidence, nothing but an exaggeration of the hæmic impulse in the aorta, accompanied by pain. I prescribed twenty-grain doses of iodide of potassium three times a day, and applied a belladonna plaster over the chest wall where the pain was felt. I also put the patient on a diet restricted as much as possible as to liquids. The only cause to which I could attribute aneurism was increased tension applied to an artery weakened at some former period by rheumatic inflammation. This tension was perhaps brought about by the fiequent efforts required in drawing corks. Anyone who has drawn a tight cork knows the powerful strain brought to bear by this act on the arteries when the chest muscles are all fixed, and we find that apoplexy has not unfrequently resulted from such efforts.

Under the treatment indicated, and with the occasional use of sedatives, the cough was relieved, but recurred occasionally, and a continuous feeling of tension remained in the chest, with intermittent pains. I endeavoured to discover increased friction by observing the profile of the chest, and by fastening to the chest wall by wax a small flag, and watching the shadow projected by this on the wall of the room. Still, the diagnosis was very doubtful, and I sent the patient to my friend Georse F. Cooper, Esq., surgeon to the British Naval Hospital, who more or less endorsed my opinion, aud concurred as to the treatment adopted. Things went on in this way until the month of September, 1880 , when, after an ahseuce of a month, I was called to see the patient, and, to my regret, found the diagnosis confirmed by the presence of pulsating tumour between the second and third ribs, about an inch to the right of the sternum. The tumour was about the size of half a small walnut, flattened and pulsating strongly, almost synchronously with the heart. The skin over the swelling was reddened, almost purplish in hue, thinned and evidently rapidly about to give way ; the pulsation was only too evident, and raised forcibly the heal of the auscultator, who felt too well the heavy thud of the blood rushing from a hypertrophied heart against the frail barrier which separated the patient from the tomb.

A slight systolic murmur was now audible over the aortic valves, and this was propagated up the vessel into the tumour. Pain had diminished owing to the pressure being now exercised more in the soft, yielding coverings of the intercostal space than in the ribs. I now prescribed complete rest, aud applied the poles of a twenty-cell Stöhrer constant current battery over the tumour for twentv minutes. This was repeated at intervals of a few days until the surface touched by the negative pole became blistertd. The iodide of potassium and dietetic treatment were crintinued. No improvement took place, and the walls of the tumour were daily becoming thinner and more prominent. My friend, Dr. E. T. von Schröders, a distinguished physician here, saw the case, but demurred to the treatment bv galvanopuncture which I proposed, owing to the unfavourable statistics hitherto shown in Europe.

As the tumour was on the point of giving way, I explained the case fully to the patient, and asked Mr. Cooper to assist me. This gentleman fully concurred in my opinion that galvano-puncture was the only treatment left which offered any hope of saving the man's life. Accordingly, on the 1st October, 1880, assisted by Mr. Cooper, I introduced two gilt needles, insulated within an inch of their points by gutta-percha recently applied, at one inch apart, into the tumour, and passed for twenty minutes a current of eight cells Stöhrer, gradually increased at one minute intervals to twelve cells. The needles were passed about an inch and a quarter into the blood-current and kept steady. The patient, a man of heroic courage, was laughing and jesting during the operation, so much so that $I$ had to chide him. He said he was quite aware of his danger, and if he were to die on the spot was contented and fearless. No burning or other uneasiness was felt during the presence of the needles in the tumour; no increased redness of the skin was produced; no corrosion of the needles took place (fine steel gilt needles, furnished by Yeates of Dublin). On withdrawing them I covered the punctures with collodion. I then applied the poles of the battery with moistened sponge to my forehead, and was surprised to find that the current was so weak as to be scarcely perceptible. The battery had, in fact, become weakened by previous use, and, owing to some dirt in the connector of the commutator, its action had become almost nil. So that, to be perfectly frank, I must admit that any good resulting in this case was due in great measure to the physical coagulation of fibrine round the needle points, in dependently of the little electrolytic action exercised by such a weak current. I had no galvanometer to test the exact strength of the current. However, I continued the medicinal and dietetic treatment, and as the patient felt no uneasiness, I left him undisturbed for some ten days, and at the end of that time met my friend Cooper at the bedside, when he exclaimed, "By Jove, there is a great improvement here!" and, to my agreeable surprise, I found the tumour perfectly hard, flattened down to the ordinary chest level, the pulsation had disappeared, the redness of the surface had gone, all the symptoms of threatened perforation had vanished, and the patient felt perfectly comfortable, without pain, without cough, without pulsation, except a general expansile fulness evident on pressing the open hand over the chest wall, and which caused him no inconvenience. The bruit had also disappeartd. Under these circumstances I prescribed perfect rest for some weeks, and continued the iodide of potassium at intervals, with a generally restricted diet, limiting as much as possible the amount of liquids taken by the patient.

Eight months have pas:ed away. The patient derlares he never felt better; he pursues his ordinary avocailons both in and out of doors; suffers from slight dry congh at times, but feels capable of any exertion. I warn him oceasionally to be careful and to take less whisky, but the temptation of frequent "calls to the bar" are too much for him, and I fear some day alcoholic excitement and anger may bring matters to a catastrophe. I do not pretend to have completely cured this patient, for aneurismal enla rgement of the aorta undoubtedly still exists; but what I do claim for the needles is, that by their use I warded off imminent death, and prolonged the existence of this patient up to the present in a condition of usefulness and comfort. Valparaiso.

Coombe Lying-In Hospital, DUblin.-A donation of $£ 1500$ from a Mrs. Tighe has been received by the governors of this hospital, and it has been resolved that a ward in the institution shall be named "The Robert Tighe Ward," in commemoration of the generous gift. 